\title{
CALCULATIONS OF GROUND FREEZING DEPTH UNDER BARE AND COVERED WITH THE SNOW COVER GROUND SURFACE FOR THE SITE OF THE METEOROLOGICAL OBSERVATORY OF LOMONOSOV MOSCOW STATE UNIVERSITY FOR WINTER PERIODS OF 2011/12-2017/18
}

\author{
D.M. Frolov \\ Geographical faculty, Lomonosov Moscow State University, Leninskie gory, 1, 119991
}

Автор для переписки: denisfrolovm@mail.ru

Citation: Frolov DM, 2019. Calculation of ground freezing depth under bare and covered with the snow cover ground surface on the site of the meteorological observatory of Lomonosov Moscow State University for winter seasons of 2011/12-2017/18. Environmental dynamics and global climate change. 10:86-90. https://doi.org/10.17816/edgcc21203

The calculating scheme for estimation of ground freezing depth under bare and covered with the snow cover ground surface on basis of air temperature and snow cover thickness is constructed and the example of calculations is performed for the site of the meteorological observatory of Lomonosov Moscow State University for winter periods of 2011/12-2017/18. The comparison of results of estimation scheme and observations indicated good correspondence.

Key words: Snow cover, ground freezing, air temperature

Построена расчётная схема для определения глубины промерзания под оголённой и покрытой снегом поверхностью на основе данных о температуре воздуха и толщине снежного покрова и произведён пример расчёта для площадки метеообсерватории МГУ за зимние периоды 2011/12-2017/18. При сопоставлении результатов расчётов и измерений на площадке метеорологической обсерватории МГУ получено хорошее соответствие.

Ключевые слова: Снежный покров, промерзание грунта, температура воздуха.

\section{BBEQ타느}

Термический режим зимних периодов и особенности снегонакопления во многом определяют термический режим подстилающих грунтов и глубину их сезонного промерзания. Согласно известным данным о среднем многолетнем режиме накопления снежного покрова и сезонного хода температуры для конкретного региона и на основании строительных норм и правил определяются средняя глубина промерзания и заложения подземных линейных коммуникаций. Однако изменения в процессе внутри сезонного накопления снежной толщи и изменения температуры по отношению к средним значениям ведут к отклонениям в изменении температуры грунта, экстремальным отклонениям значений глубины промерзания и опасностям для заложенных линейных сооружений.

Также изменение абсолютных значений температуры грунта и её динамики важно для развития микробиоты и корневых систем деревьев и растений. И, кроме того, как известно, накопление снежного покрова может вести к деградации многолетней мерзлоты в зоне её непрерывного распространения, а отсутствие снежного покрова - к возникновению мерзлоты в зоне её прерывистого (островного) распространения или отсутствия.

Поэтому В.А. Кудрявцев [Кудрявцев, 1954] охарактеризовал отепляющее и охлаждающее действие снежного покрова на грунт в зависимости от режима снегонакопления и продолжительности его залегания и предложил уравнение для оценки глубины промерзания, включающее высоту снежного покрова, теплофизические свойства снега и амплитуду годовых колебаний температуры воздуха. В работе же А.В. Павлова [Павлов, 1966] снежный покров на поверхности почвы рассматривался как фиктивный дополнительный слой с эквивалентным термическим сопротивлением, и это использовалось в формуле для расчёта глубины сезонного промерзания. Современное продолжение этих работ можно найти в диссертации Е.Е. Мачульской [Мачульская, 2001] и также в работах зарубежных авторов [DeGaetano et al., 2001, Jafarov et al., 2012]. 


\section{ПОСТАНОВКА ЗАПАЧИ}

Для оценки роли снежного покрова в промерзание грунта нами были произведены расчёты глубины промерзания на основе данных о температуре воздуха и толщине снежного покрова по данным метеообсерватории МГУ для оголённой и покрытой снегом поверхности за зимние периоды 2011/12-2018/19. Описание почвы и микроклиматических условий, а также анализ измерений глубины промерзания на оголённой и имеющей естественный покров экспериментальной площадке метеообсерватории МГУ мерзлотомерами Данилина и Ратомского за 1955-2013 годы дан в работе [Корнева, Локощенко, 2015]. Нами были произведены расчёты и сравнение расчётной глубины промерзания за эти зимние периоды с фактически наблюдаемой глубиной промерзания, используя [Эколого-климатические..., 2012-2019]. Вообще оценка разности температуры приземного воздуха зимой и покрытой снегом поверхности почвы на территории Евразии была дана в работе [Шерстюков, Анисимов, 2018].

Расчётная схема для случая открытой поверхности грунта строилась на основе задачи теплопроводности двух сред (мерзлый и талый грунт) с фазовым переходом на границе между ними, а для случая покрытой снегом поверхности на основе задачи теплопроводности трехслойной среды (снег, мерзлый и талый грунт) также с фазовым переходом на границе. Уравнение теплового баланса включало энергию фазового перехода, приток тепла из талого грунта и отток в мерзлый грунт и при наличии снежного покрова через него в атмосферу. Поток тепла рассчитывался по закону Фурье, как произведение теплопроводности и градиента температуры. Предполагалось, что температура в каждой из сред изменяется линейно. Для снежного покрова и мерзлого грунта использовалась формула теплопроводности двухслойной среды.

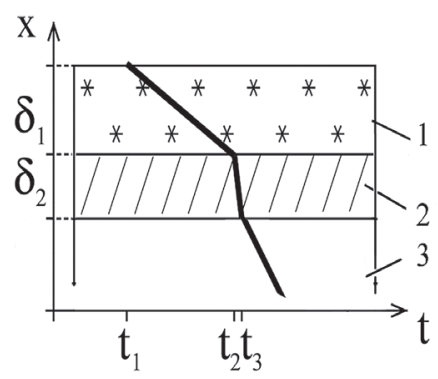

Рис. 1. Распределение температуры в среде, состоящей из снежной толщи (1), слоя мерзлого (2) и слоя талого грунта (3)

Fiહ. 1. Temperature distribution in the media, consisting of snow cover (1), layer of frozen (2) and thawed ground (3)

\section{MATEMATИЧECKOE MOЯEПИPOBAHИE}

Расчет промерзания грунта, на основе данных о температуре воздуха (и толщине и теплопроводности снежного покрова) в течение зимнего периода позволяет оценить интенсивность движения фронта промерзания в этот период времени. Зависимость скорости движения фронта промерзания находится по расчетной схеме. Схема учитывает промерзание грунта снизу на массиве мерзлого грунта в зимний период на основе данных о ежедневной температуре воздуха (и толщине и теплопроводности снежного покрова). Уравнение теплового баланса на границе фронта промерзания записывалось как $F_{1}=c L V+F_{2}$ или как:

$$
d h_{f g} / d \tau=V=\left(F_{1}-F_{2}\right) / c L,
$$

где:

$F_{1}$ - отток тепла через замёрзший грунт (и снежный покров) от фронта промерзания $\left(\mathrm{BT} / \mathrm{M}^{2}\right)$ в атмосферу;

$c L V=c L d h_{\text {мг }} / d \tau$ расход тепла на фазовый пе-

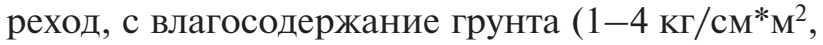
или с долей содержания влаги $0,1-0,4$ от общего объёма среды, где максимальное значение содержания влаги, равное 0,4 (которое было принято при расчётах) соответствует полному заполнению пор водой у легкой глины с плотностью 2000 кг $/ \mathrm{M}^{3}$ и коэффициентом пористости 0,617 [Грунтоведение, 2005]);

$L$ - энергия фазового перехода (335 кДж/кг), $V$ - скорость движения фронта промерзания $(\mathrm{cm} / \mathrm{c})$;

$F_{2}$ - отток тепла на охлаждение талого грунта перед фронтом промерзания (Вт/м²).

При составлении уравнения баланса тепла было сделано пренебрежение слагаемыми, отвечающими за теплопотери на охлаждение грунта, а также за изменение его влажности с глубиной.

Тепловой поток через замёрзший грунт от фронта промерзания в атмосферу в случае отсутствия снежного покрова выражается по закону Фурье через градиент температуры и теплопроводность как $F=-\lambda(\operatorname{grad} T)$ :

$$
F_{1}=-\lambda \frac{\Delta T}{\Delta x}=\lambda_{\text {мг }} \frac{-T_{\text {возд }}}{h_{\text {мг }}} .
$$

А в случае наличия снежного покрова теплопроводность и тепловой поток через комбинацию из двух сред (снег и мерзлый грунт) согласно данным справочника [Михеев, 1977] может быть выражена как:

$$
F_{1}=-\lambda \frac{\Delta T}{\Delta x}=\frac{-\Delta T}{\left(\frac{\Delta x_{\mathrm{c}}}{\lambda_{\mathrm{c}}}+\frac{\Delta x_{\mathrm{MI}}}{\lambda_{\mathrm{M \Gamma}}}\right)}=\frac{-T_{\text {возд }}}{\left(\frac{h_{\mathrm{c}}}{\lambda_{\mathrm{c}}}+\frac{h_{\mathrm{MI}}}{\lambda_{\mathrm{MI}}}\right)} .
$$


Здесь $T_{\text {возд }}-$ температура воздуха, $h_{\mathrm{c}}$ и $h_{\mathrm{мг}}-$ толщина снега и глубина промерзания, а $\lambda_{c}$ и $\lambda_{\text {мг }}$ - теплопроводность снега и мёрзлого грунта и это выражение совпадает с предыдущим при $h_{\mathrm{c}}=0$.

Предполагалось, что на глубине 10 м в грунте находится точка нулевых годовых колебаний температуры $T_{0}$ со значением около $7{ }^{\circ} \mathrm{C}$ (значение привязывалось к среднегодовой температуре в Москве). Поэтому

$$
F_{2}=-\lambda_{\text {тг }} \frac{\Delta T}{\Delta x}=\lambda_{\text {тг }} \frac{T_{0}}{10-h_{\mathrm{M \Gamma}}} .
$$

Здесь $\lambda_{\text {тг }}-$ теплопроводность талого грунта. Вычисления производились с шагом в один день. На первый момент предполагалось, что толщина мерзлого грунта $h_{\text {мг }}$ равна $0,5 \mathrm{~cm}$. На каждом шаге по времени (каждый день) вычислялась (рассчитывалась) скорость промерзания $V$ и значение толшины мерзлого грунта $h_{\text {мг }}$ для следующего дня (шага по времени). Согласно [Грунтоведение, 2005], средняя теплопроводность талого и мерзлого глинистого грунта может быть взята как 1,4 и 1,8 Вт/м ${ }^{\circ} \mathrm{C}$.

Средняя теплопроводность снега $\lambda_{\text {c }}$ рассчитывалась относительно плотности по формуле А.В. Павлова [Павлов, 1979] и бралась равной $0,18 \mathrm{BT} / \mathrm{M}^{\circ} \mathrm{C}$.

Была построена разностная схема посредством аппроксимации выведенного дифференциального уравнения для изменения глубины промерзания грунта явным методом Эйлера:

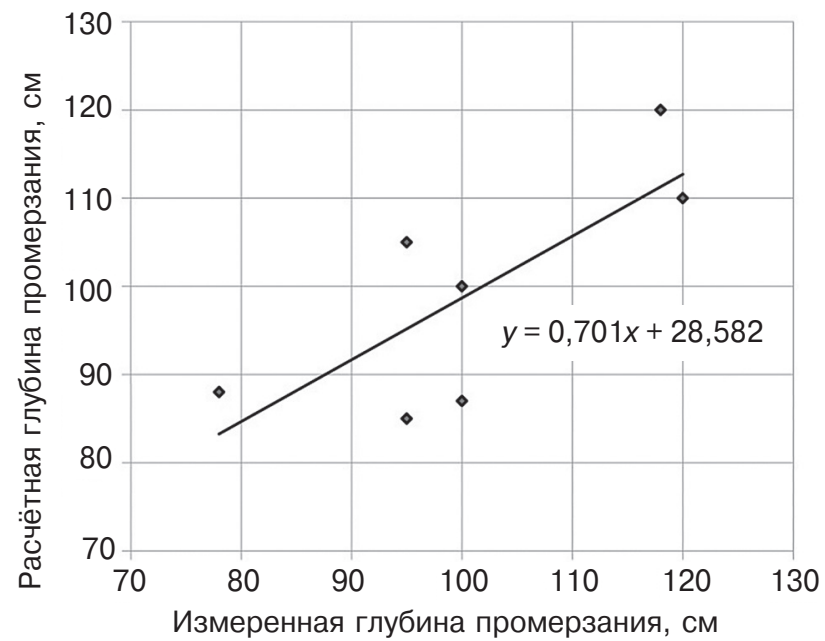

Pnс. 2. Расчётная и измеренная максимальная глубина промерзания под открытой поверхностью для площадки метеообсерватории МГУ за зимние периоды 2011/12-2017/18

Fis. 2. Maximal ground freezing depth under bare site surface of the meteorological observatory of Lomonosov Moscow State University for the winter periods of 2011/12-2017/18 (comparison of observed and calculated data and trend line $y=0,7 x+28,6)$
$h_{\mathrm{M \Gamma}}\left(t_{\mathrm{n}+1}\right)=h_{\mathrm{Mг}}\left(t_{\mathrm{n}}\right)+\Delta t V\left(t_{\mathrm{n}}\right) . \quad$ По полученной разностной схеме для каждого зимнего периода 2011/12-2018/19 были произведены расчёты изменения глубины промерзания грунта и сравнение полученных результатов расчётов с данными фактических наблюдений для оголённой и покрытой снегом поверхности площадки МО МГУ для каждого дня зимнего периода.

\section{РЕЗУПЬTАТЫ РАСЧЁТОВ И ОБСУЖПЕНИЕ}

Результаты расчета максимальной глубины промерзания под открытой поверхностью для площадки метеообсерватории МГУ за зимние периоды 2011/12-2017/18 и их сравнение с данными наблюдений приведены на рисунке 2 и в таблице 1.

Из таблицы 1 видно, что средняя разность расчётной и измеренной максимальной глубины промерзания под оголённой поверхностью для площадки метеообсерватории МГУ за зимние периоды 2011/12-2017/18 составляет 1,6 см, а под поверхностью с естественным покровом - 4 см.

Пример результатов расчёта изменения глубины промерзания для оголённой и покрытой снегом поверхности и её сравнение с измеренными значениями для одного из зимних периодов дан на рисунке 3.

\section{Table 1 / Таблица 1}

Сопоставление расчётной и измеренной максимальной глубины промерзания поА оголённой поверхностью и поверхностью с естественным покровом А^я площаАКи метеообсерватории МГУ за зимние периоАы 2011/12-2017/18.

Comparison of calculated and observed maximal ground freezing depth under bare and covered with snow site surface of the meteorological observatory of Lomonosov Moscow State University for the winter periods of $2011 / 12-2017 / 18$.

\begin{tabular}{|c|c|c|c|c|}
\hline \multirow[t]{2}{*}{$\begin{array}{l}\text { Зимний } \\
\text { периоА }\end{array}$} & \multicolumn{2}{|c|}{$\begin{array}{c}\text { Максимальна глубина } \\
\text { промерзания грунта } \\
\text { поА оголённой } \\
\text { поверхностью, см }\end{array}$} & \multicolumn{2}{|c|}{$\begin{array}{c}\text { Максимальна глубина } \\
\text { промерзания грунта } \\
\text { поА естественным } \\
\text { покровом, см }\end{array}$} \\
\hline & измеренная & расчётная & измеренная & расчётная \\
\hline $2011 / 12$ & 120 & 110 & 18 & 10 \\
\hline $2012 / 13$ & 118 & 120 & 8 & 12 \\
\hline $2013 / 14$ & 100 & 87 & 18 & 4 \\
\hline $2014 / 15$ & 95 & 85 & 30 & 7 \\
\hline $2015 / 16$ & 78 & 88 & 25 & 30 \\
\hline $2016 / 17$ & 100 & 100 & 3 & 7 \\
\hline $2017 / 18$ & 95 & 105 & 14 & 18 \\
\hline Макс. разн. & \multicolumn{2}{|c|}{13} & \multicolumn{2}{|c|}{23} \\
\hline Мин. разн. & \multicolumn{2}{|c|}{-10} & \multicolumn{2}{|c|}{-5} \\
\hline Сред. разн. & \multicolumn{2}{|c|}{1,6} & \multicolumn{2}{|l|}{4} \\
\hline
\end{tabular}




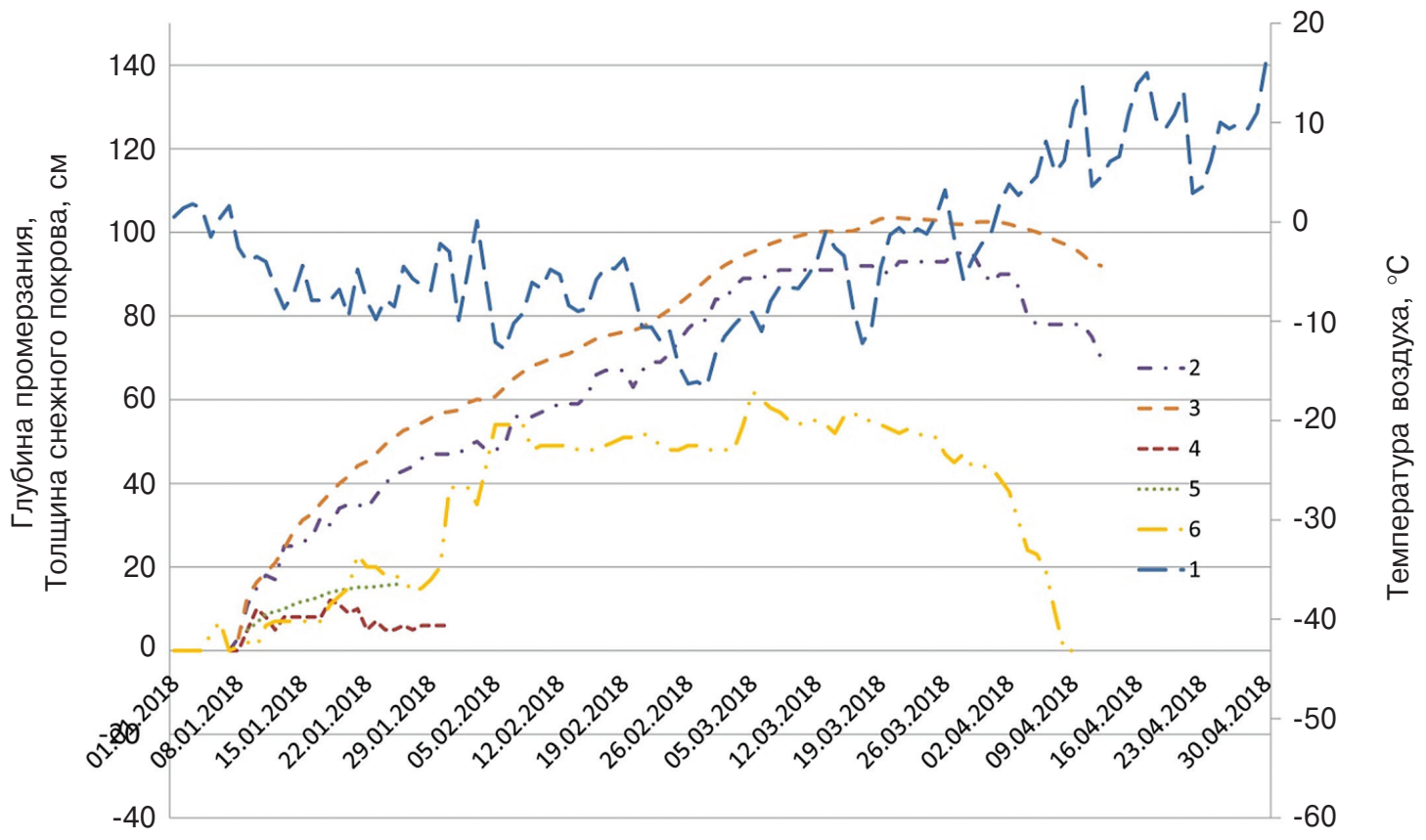

Pnc. 3. Изменения температуры воздуха и глубины промерзания по данным расчётов и наблюдений для открытой и покрытой снегом поверхности грунта для метеостанции МГУ для зимнего периода 2017/18 (1 - температура воздуха, 2 - наблюдаемая и 3 - расчётная глубина промерзания под открытой поверхностью, 4 - наблюдаемая и 5 - расчётная глубина промерзания под естественным покровом, 6 - толщина снежного покрова)

Fiø. 3. Variations of air temperature and ground freezing depth according to the data of calculations and observation under bare and covered with snow site surface of the meteorological observatory of Lomonosov Moscow State University for the winter period 2017/18 (the results of calculations for ground freezing depth for the bare (3) and covered with snow site surface (5) and theirs comparison with the observed data (2 and 4 correspondingly). Air temperature (1) and snow cover thickness (6))

\section{3АKกIOUEHИE}

Рассмотренный метод линейных градиентов отличается от рассмотренного ранее в классическом учебнике [Тихонов, Самарский, 1999] (1-е издание - 1951 г) или у А.В. Павлова [Павлов, 1966] метода, а также от приведённых в ряде других изданиях методов. Там для расчёта сезонной динамики глубины промерзания грунта используется дифференциальное уравнение уравнения теплопроводности первого порядка по времени и второго порядка по пространству в частных производных, а здесь используется обыкновенное дифференциальное уравнение первого порядка по времени. И его решение численным методом намного проще и может легко производиться в программе Excel, хотя и требует ряд допущений и ограничений (например, требуется малый шаг расчётов по времени).

Вообще же, средняя глубина промерзания почвы в Московской области по многолетним данным наблюдательной сети ГУ «Московский ЦГМС-P» (http://ecomos.ru/kadr22/ nowostBlank.asp?fajl $=$ new21.10.09.htm) достигает 85 см при нормальных условиях температурного режима и высоте снежного покрова.
Малая глубина промерзания на метеостанции МГУ объясняется наличием обогревания почвы коммуникациями, проложенными под землей вблизи метеоплощадки [Эколого-климатические..., 2012] и обогревающим воздействием города. Получение неточных расчётных значений глубины промерзания может быть объяснено тем, что в уравнение баланса тепла не учитывался тепловой поток на охлаждение грунта, а только на фазовый переход, а также не учитывались изменения влажности грунта.

Работа выполнена по ГЗ AAAA-A16-116032810093-2 по теме 1.7 «Картографирование, моделирование и оценка риска опасных природных процессов».

\section{ПИTEPATYPA}

1. Авилова КВ, Бунина НА, Волкова ОА, 2016. Экологоклиматические характеристики атмосферы в 2015 г. по данным метеорологической обсерватории МГУ имени М.В. Ломоносова. МАКС Пресс, Москва: 268 с.

2. Ахиярова КИ, Беликов ИБ, Волкова ОА, 2015. Экологоклиматические характеристики атмосферы в 2014 г. по данным Метеорологической обсерватории МГУ имени М.В. Ломоносова. МАКС Пресс, Москва: 235 с. 
3. Беликов ИБ, Горбаренко ЕВ, Елохов АС, 2012. Экологоклиматические характеристики атмоссеры в 2011 г. по данным метеорологической обсерватории МГУ. МАКС Пресс, Москва: 230 c.

4. Беликов ИБ, Горбаренко ЕВ, Ерёмина ИД, 2013. Эколого-климатические характеристики атмосфреры в 2012 г. по данным Метеорологической обсерватории МГУ. МАКС Пресс, Москва: 207 с.

5. Беликов ИБ, Горбаренко ЕВ, Ерёмина ИД, 2014. Эколого-климатические характеристики атмосфреры в 2013 г. по данным Метеорологической обсерватории МГУ. МАКС Пресс, Москва: 168 с.

6. Тросиимов ВТ, ред, 2005. Грунтоведение. Изд-во МГУ, Наука, Москва: 1024 с.

7. Жданова ЕЮ, Локощенко МА, Богданович АЮ, 2017. Эколого-климатические характеристики атмоссреры в 2016 г. по данным метеорологической обсерватории МГУ имени М.В. Ломоносова. МАКС Пресс, Москва: 245 с.

8. Корнева ИА, Локощенко МА, 2015. Температура почвы и грунта в Москве и ее современные изменения. Метеорология и гидрология. 1:38-50.

9. Кудрявцев ВА, 1954. Температура верхних горизонтов вечномерзлой толщи в пределах СССР. Изд-во АН СССР, Москва: $183 \mathrm{C.}$

10. Локощенко МА, 2019. Эколого-климатические характеристики атмосфреры Москвы в 2018 г. по данным метеорологической обсерватории МГУ имени М.В. Ломоносова. МАКС Пресс, Москва: 277 с.

11. Локощенко МА, Жданова ЕЮ, Богданович АЮ, 2018. Эколого-климатические характеристики атмосферы Москвы в 2017 г. по данным Метеорологической обсерватории МГУ имени М.В. Ломоносова. МАКС Пресс, Москва: $240 \mathrm{c}$.

12. Мачульская EE, 2001. Моделирование и диагноз процессов тепловлагообмена между атмоссрерой и сушей в условиях холодного климата [дисс. на соискание ученой степени к.ф.м.н.] Москва: 125 с.

13. Михеев МА, Михеева ИМ, 1977. Основы теплопередачи. Энергия, Москва: 344 с.

14. Павлов АВ, 1966. Инженерно-геологические прогнозы глубины промерзания и протаивания грунтов. В: Материалы 8-го Всесоюзного междуведомственного совещания по геокриологии (мерзлотоведению), Якутск.

15. Павлов AB, 1979. Теплосризика ландшафртов. Наука, Новосибирск: 284 с.

16. Тихонов АН, Самарский АA, 1999. Уравнения математической фризики. Издательство московского университета, Москва: 799 с.

17. Шерстюков АБ, Анисимов АО, 2018. Оценка влияния снежного покрова на температуру поверхности почвы по данным наблюдений. Метеорология и гидрология. 2:17-25.

18. DeGaetano AT, Cameron MD, Wilks DS, 2001. Physical simulation of maximum seasonal soil freezing depth in the united states using routine weather observations. Journal of Applied Meteorology 40:546-555.

19. Jafarov EE, Marchenko SS, Romanovsky VE, Numerical modeling of permafrost dynamics in Alaska using a high spatial resolution at a set. The Cryosphere 6:613-624. doi:10.5194/tc-6-613-2012.

Поступила в редакцию: 19.10.2018 Переработанный вариант: 15.06.2019 